\title{
Exploring Benefits of Local E-Commerce for Enhancing Firm's Competitiveness
}

\author{
Julien Hildebrandt
}

Abertay University, United Kingdom

\begin{abstract}
:
The purpose of this paper is to explore the possibilities offered by local e-commerce solutions to increase the competitiveness of local bakery stores. This study follows an inductive qualitative research guided by grounded theory approach. The web-based questionnaires were used to get opinions of bakery goods consumers and the management board of a bakery goods firm participated in this study, which was geographically limited to the bakery sector in Germany. The value of this study is in initiating the development of theory on benefits of local e-commerce. It introduces consumers as well as companies to a new dimension of distributing or purchasing products and therefore, should encourage both parties to make use of local e-commerce solutions.
\end{abstract}

Paper type: Research paper

Keywords: Local e-commerce, Competitiveness, Customer Awareness, Small Business Strategy 


\section{Introduction}

Local small businesses often faced competition from multinational firms as well as internet start-ups especially from those innovative and moving-fast companies. The dramatic growth in online retailing over the past decade represents a challenge to brickand-mortar businesses. The Retail outlets such as bookstores and mobile phones shops have been struggling while online retailing continues to grow. This changing shopping trend could be an opportunity for the bakery sector, if the bakeries could take advantages of the e-commerce

One of the challenges faced by small bakeries is highly competitive nature of the bakery industry. With volume growth in bakery products by $11 \%$ in 2006-2012, Germany is among the top bread-consuming countries in Western Europe (Euromonitor, 2013). The German bakery industry is highly fragmented where traditional bakeries are competing with bakery departments in supermarkets (Euromonitor, 2013) as well as new entrants such as ethnic breads or niche bakeries (International Market Bureau, 2010). On top of that, the German consumers are increasingly price conscious due to global financial crisis (Euromonitor, 2013; International Market Bureau, 2010). The competition on price (Porter 2001) poses a challenge for artisan bakeries due to the higher cost of production compared to the mass-produced industrial bakeries.

To address these issues and challenges the use of local e-commerce solutions is suggested. Local e-commerce as a concept does not exist at the moment but it should combine the advantages of e-commerce and local trade, therefore the concepts of local trade and e-commerce in the context of the bakery sector are analysed. Further, the problem of small bakeries to raise awareness of customers and to increase competitiveness locally should be solved through local e-commerce solutions.

There are two different and somewhat opposing perspectives in regards to the impacts of e-commerce to local trade. On the one hand there is a view that local trade will become extinct through the rise of e-commerce businesses (Andreessen 2013). On the other hand there is an argument that e-commerce is not the death of local trade because it cannot replace local trade (Zimmer 1999); rather, the availability of digital channels such as online stores and mobile applications stores -- enhances the shopping experience for the customer. There is a growing trend for retailers to adopt multiple distribution channels which often comprise of both offline and online channels. Amazon is an exemplar here. Amazon, one of the largest online retailers in the world, has opened its first physical store in 2015 (Johnston, 2015). The decision of Amazon to run a physical store reflects the need to offer a seamless and innovative customer experience.

The key objectives of this study include identification of consumer preferences and buying patterns in purchasing bakery goods online and offline, and the effects of local e-commerce on the immediate business environment.

International Journal of Management and Applied Research, 2015, Vol. 2, No. 1 


\section{Conceptualising local e-commerce}

Local e-commerce is a combination of the concepts of local trade and e-commerce. Based on the definition of e-commerce (Manzoor 2010), local e-commerce can be described as the application of electronic means and technologies for the sales of local goods. Local e-commerce comprises of purchase, service and information of commerce including within business, business-to-business and business-to-customer interactions. Putting this together, local e-commerce can be referred to online transaction that heavily involves localised operations. Local e-commerce solutions include e-commerce sites, mobile shopping applications, and social media. The trial of Facebook and Twitter "buy" button which enables their users to purchase items directly from the social networking sites without having to be directed away from the social network indicate a new wave of online shopping.

While there are mounting studies dedicated to the adoption of e-commerce by small businesses, little is known about the usage and potential of e-commerce solutions to local food movement. The bakery sector, in particular, could be benefited from the local e-commerce. First, having pre-orders via the internet allows the bakeries to bake their products on demand thereby increase efficiency (Porter 2001). Second, bakeries could also reduce running costs and avoid processing errors by implementing e-commerce (Heinemann et al. 2013; Zhang et al. 2011). Third, bakeries could reach wider consumer base by engaging in promotional activities over the internet. Social media, for instance, allows bakeries to send personalised marketing message to their target consumers at a fairly low cost. Studies have shown that, if used properly, social media could be an effective to increase visibility and consumer trust in the brand (Muller et al. 2011; Niranjanamurthy et al. 2013; Zhang et al. 2011). Nevertheless, the company has to employ the right strategy and qualified staff in order to exploit the benefits of local ecommerce.

There are several benefits for the customers in using local e-commerce. First, the customers can make purchases at any point of time (Niranjanamurthy et al. 2013) and pick them up during the opening hours of the local stores, where the customer collect the product at their convenient time. Alternatively, the customers could receive the product at their home or office. This provides the customers a greater convenience of having the products delivered rather than visiting the store physically. Second, the customer could order a customised or personalised product (Porter 2001) through online configuration and pick it up in the store with the guarantee of freshness. Third, a positive customer experience leads to repeat purchase and positive word-of-mouth. Customers expect seamless shopping experiences in both online and offline channels. The opportunity to shop on the move via tablets or smartphones not only enhances customers' shopping experience but also allows merchants to promote their products and services in a more efficient way.

\subsection{Anticipated outcome of local e-commerce}

The anticipated outcome of using local e-commerce solutions is to provide the customer shopping experiences with an alternative to shop online by exploiting the advantage of quick and easy shopping through e-commerce components. The combination of 
physical and online presence is increasingly popular in retailing. Such distribution strategy involves a highly organised delivery to customers, which is often delivered on a next day basis in order to maximise their revenue growth. The decision of Amazon to open a physical store illustrates the importance of having both online and offline distribution channels (Arnold 2014). E-commerce revenues could be increased through customers who started to put trust in the company after having bought via local ecommerce and therefore decided to buy online from that point on. Through all these factors the competitiveness and customer awareness can be increased and a high customer satisfaction can be ensured.

As part of the e-commerce concept, mobile commerce (m-Commerce) can be described through the given e-commerce definition with the addition of mobile device usage (Tanh 2000). Additional features and possibilities are available through $\mathrm{m}$-Commerce, especially location based services (Timmers 2000) such as local discounts offers and GPS tracking. The convenience of mobile shopping meets the demand for busy consumers in contemporary life. Therefore, m-Commerce will be included in this study.

Through analysis of literature the following theoretical framework and research questions are developed. The first research question is that, to what extent local ecommerce can improve competitiveness of small bakery locally? This research question focuses on the key concepts of competitiveness, customer awareness and how those can be influenced by local e-commerce. The second research question narrows the subject of matter down to: what are the key attributes of an effective local e-commerce solution in the bakery sector? Here the focus is on the attributes of the key concept local ecommerce, which is influenced by the concepts of local trade, e-commerce and $\mathrm{m}$ Commerce. This question is helpful in the research because it identifies the attributes of local e-commerce, which are important to identify its influences on competitiveness, customer awareness and the business strategy.

The theoretical framework derived from the literature is described in figure 1. The concept of local e-commerce is influenced by local trade, e-commerce and $\mathrm{m}$ Commerce. In this research study local e-commerce is analysed with special attention to how it influences competitiveness and customer awareness and how local e-commerce solutions can help a small bakery to become more competitive locally. Furthermore, the influences of local e-commerce on profit, costs, employees and marketing are analysed.

International Journal of Management and Applied Research, 2015, Vol. 2, No. 1 
Figure 1 Theoretical framework

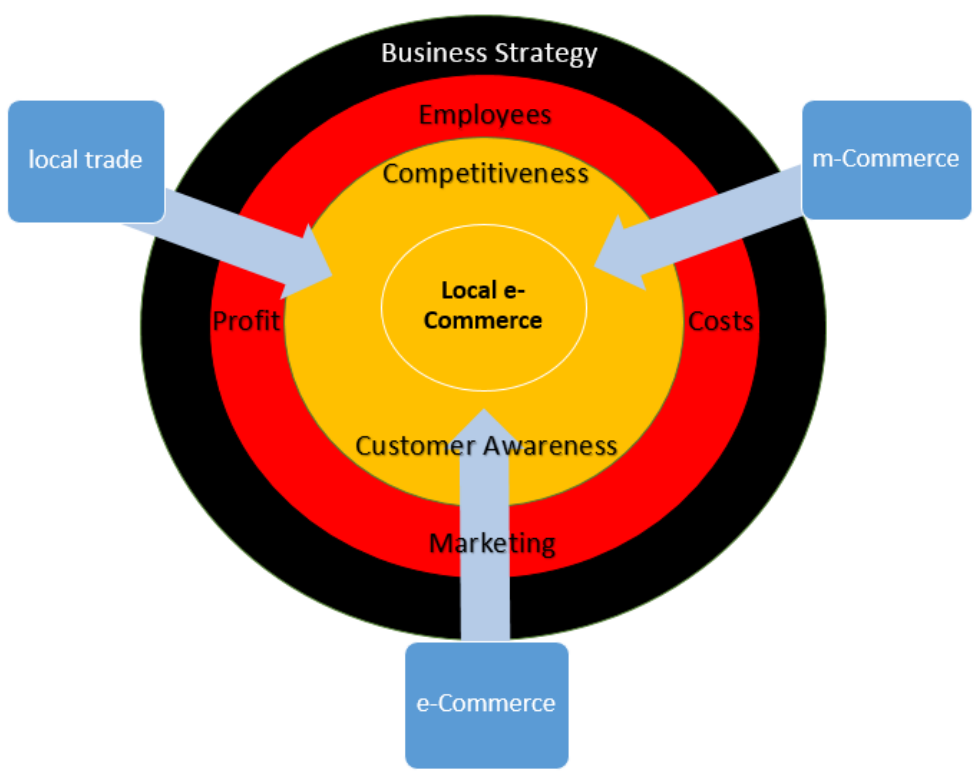

\section{Methodology}

Moreover, the research of this study focused on people instead of objects and further analysed humans as social actors as well as the difference between humans in their roles (Yu 2011). Additionally, humans can interpret their everyday social role by different customer perceptions regarding their purchase decisions in local e-commerce. In this decision-making process people interact in a symbolic interactionism manner during which they undergo a continuous process of interpreting the action as well as with whom they are interacting, which leads to the adjustment of their own meaning e.g. buying via local e-commerce because a friend does it (Saunders, Lewis and Thornhill 2012).

The researcher is aware that his own values are leading to a value bound axiology which influences all research stages (Heron 1996) by influencing the language element to understand the phenomenon as well as influencing the previous knowledge about the research topic, so that the researcher is part of the research and cannot be separated from it (Saunders, Lewis and Thornhill 2012). Thus, the view on the role of values in the research is also subjective. The researcher is part of the local e-commerce research as described above.

This study is based on qualitative data collection which aligns with the interpretivism philosophy (Burrell and Morgan 1982) as the subjective and social meanings of the people of the studied phenomenon will be considered (Gephart and Robert 2004). The qualitative research design is suited well for in-depth investigations of smaller samples.

The research approach is of an abductive kind, which fits well with the interpretive philosophy and a qualitative research design. Thus, the abductive approach serves to generate or modify theory that uses data collection to explore its phenomenon as well as known premises to create testable conclusions (Easterby-Smith et al 2008). Therefore, it is possible to generalise from interactions between the specific and the general (Yin

International Journal of Management and Applied Research, 2015, Vol. 2, No. 1 
2009). Through this it can be shown that through the use of local e-commerce the customer awareness and competitiveness of a small baker company can be increased. This perspective is tested in the research and theory about local e-commerce is generated.

\subsection{Sampling}

Saunders et al. (2012) recommend a minimum non-probability sampling size of 12-30 people for a heterogeneous population by using snowball, convenience and selfselection sampling. For this reason a sampling size of 61 participants was chosen for this study.

Additionally, the Bäckerei Konditorei Schmidt e.K. (Bäckerei Konditorei Schmidt e.K. 2014), a bakery and confectionary artisan business was researched. The participants of the research were split into two categories: managers and consumers. There were four participants of the management category concerning the research of the company. The participants of both categories were recruited by the use of volunteer based snowball sampling as well as convenience sampling also known as availability sampling, where initial participants were recruited via the Facebook university group and Facebook requests. Additionally self-selection sampling through direct communication via e-mail to employees as well as the management of the above mentioned company was used to recruit participants.

This study was conducted via qualitative questionnaires consisting of a set of questions and statements which the participants were required to respond to in a predetermined order as part of a survey strategy (deVaus 2002). For the data collection self-completed web-based questionnaires were used because of the high sample size, so that participants were recruited geographically dispersed (Saunders et al., 2012) in order to avoid influences through only local research and to reach a reliable opinion about local e-commerce. Additionally this method supported the aim to reach the desired high sample size within the limited timeframe of this study.

The mono-method qualitative research of web-based questionnaires was conducted with Google Documents and recruited participants via Facebook and e-Mail. This survey combined closed- and open-ended questions. The combination of both kinds of questions helped to identify the consumer opinions, needs, behaviour and possibilities of local e-commerce as well as the managers' point of view towards local e-commerce.

The collected qualitative data was large in volume, non-standardised and complex, which made it time-consuming to analyse. As aids to analyse the collected data interim summaries and self-memos were used to reduce the complexity and volume of the collected data and further to record ideas when they occurred (Miles and Huberman 1994).

For the analysis of some questions data was sorted into different categories so that the data was allocated into analytical categories to enable further analysis of those and of the thereby formed patterns. This categorisation helped to answer the research questions and objectives. The data was categorised data driven and the categories were derived from data (Strauss and Corbin 1998).

Further, the propositions of both participant groups that emerged inductively were confronted with each other with the aim to find alternative explanations of local e-

International Journal of Management and Applied Research, 2015, Vol. 2, No. 1 
commerce in order to formulate valid theory and conclusions (Miles and Huberman 1994). Some qualitative data was analysed by quantifying it in order to show frequencies of particular answers that were given by the participants and to finally visualise and present them in a simplified way (Hannah and Lautsch 2011).

Data was analysed with the grounded theory approach which develops a grounded theory that emerged from the data (Khan 2014), here the sample delivered data related to the research questions and objectives (Corbin and Strauss 2008). This approach was most suitable for the research because it concentrates on the creation of knowledge regarding the topic of local e-commerce. The ethics approval of this study has been received.

\section{Data Analysis and Findings}

\subsection{Findings of the consumer survey}

For the consumer survey 61 participants of different age groups were recruited. The participants were recruited via Facebook, whereby all different ages were requested to participate. In the following the data analysis approach is presented by two examples.

The first question aims to analyse the previous knowledge of the consumers about local e-commerce. Therefore, by categorising the participant responses, it is outlined in the figure below how the made associations match the definition of local e-commerce of this research.

Figure 2: Analysis of consumer knowledge:

What do you associate with the term local e-commerce?
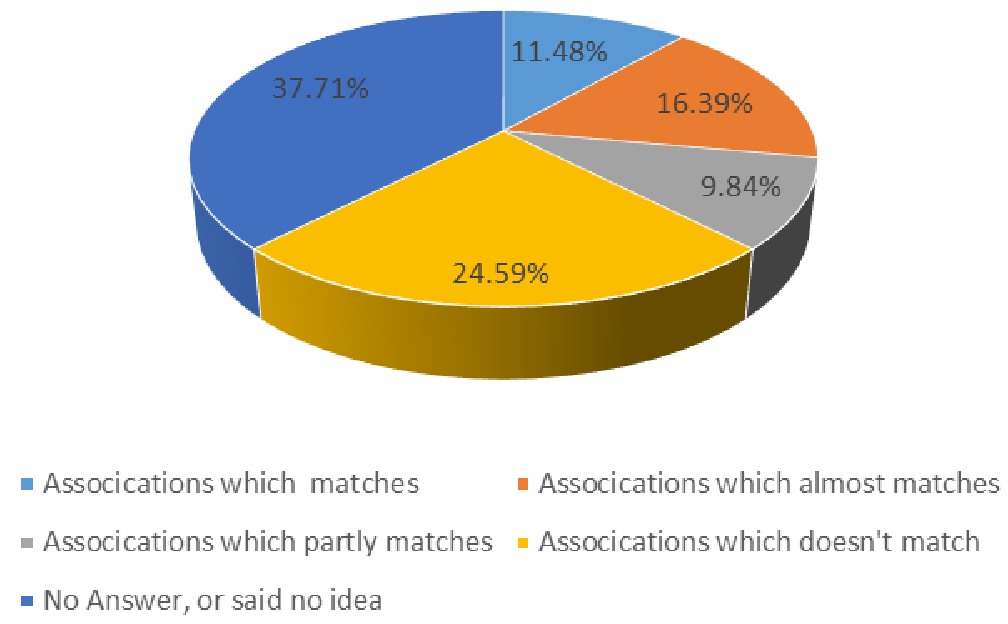

In answering to the question "what do you associate with the term local e-commerce", most respondents answered that they do not know what local e-commerce is or skipped the question, i.e. the respondents did not answered the question. The potential reasons for the low awareness of local e-commerce include the low adoption of local ecommerce solutions, and more importantly, the absence of theoretical knowledge on local e-commerce. 
Nearly a quarter of the respondents misunderstood the concept of local e-commerce. Answers such as "computer, ATM's, online banking" are allocated in this category.

$26.23 \%$ of the respondents match part of the definition of local e-commerce. These respondents mentioned "location-based" and "local businesses offer their goods online for sale". These answers made relevant associations with the definition of local ecommerce but omitted important parts of the definition of local e-commerce and thus they are categorised as "partially or almost match with the definition".

Only $11.48 \%$ of the participants made the most relevant associations in accordance with the definition of local e-commerce covering its most important aspects. In this category, answers such as "omni-channeling" and "linking of local distribution channels and online-trade" are included. In sum, the finding suggests that a fairly low level of understanding regarding local e-commerce.

The analysis of the second question outlines the willingness of people to adopt local ecommerce and their motivations of doing so.

Figure 3: Analysis of the consumer willingness:

Would you use local e-commerce?

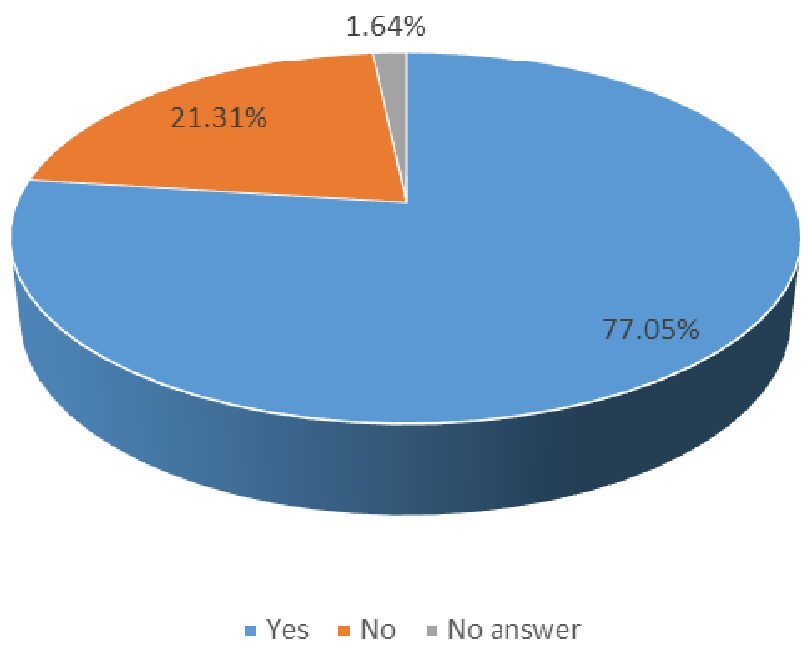

The figure above shows that majority of respondents $(77.05 \%)$ are willing to use local e-commerce solutions, whereas only $21.31 \%$ are not willing to do so. The most often mentioned reasons for using local e-commerce include greater flexibility, shorter waiting time and the higher level of convenience. Thus, the combination of the advantages of the distribution channels local trade and e-commerce is positively noted.

Through the analysis of the answers given in the consumer survey the following key findings are outlined. The results obtained from the consumer survey shown that majority of the respondents have little or no conceptual knowledge about local ecommerce. In addition to that, results also indicated that more than $75 \%$ of the respondents want to use local e-commerce. The most cited reasons to adopt local ecommerce solutions include the opportunity to ensure the availability of the product at any time, the reduced waiting time, greater convenience, and brand loyalty. The respondents also commented that the online presence and options to make purchase

International Journal of Management and Applied Research, 2015, Vol. 2, No. 1 
online would increase customer awareness, higher productivity and remain competitive in the intensified market.

The most wanted local e-commerce solutions include the online ordering system $(73.77 \%)$, online product configurator $(60.66 \%)$ and store-locator $(32.79 \%)$. By using the online ordering system the customer can order products online, while the online product configurator enables customers to configure a product online. The store-locator serves as a function that allows customers to find the nearest store to their current position. The most often mentioned reasons for these choices are time savings and convenience. The most surprising aspect of the data is in the home delivery option since only $1.64 \%$ of the respondents think that local e-commerce should comprise home delivery service.

Result shows that the most important attributes of bakery goods that influence the purchasing decision include price (37.71\%), taste (34.43\%), freshness $(27.87 \%)$, whereas size $(1.64 \%)$, consistency $(1.64 \%)$ and storability $(3.28 \%)$ are perceived as least important. This finding is consistent with the works of Euromonitor (2013) and International Market Bureau (2010) which pointed out that German consumers are price conscious towards baked products.

$44.26 \%$ of the respondents indicated that local e-commerce would make purchases of bakery goods online more attractive to them. This represents a window of opportunity for bakeries to sell online since price sensitive customers frequently compare prices before making purchase. Additionally, bakeries could target the price-conscious customers by organising promotional activities such as price reduction for bulk purchases and group buying online.

Additionally, $26.23 \%$ of the respondents said that a bakery with local e-commerce solutions would tempt them to buy there rather than from their competitors. However, nearly $40 \%$ of the respondents said that they are loyal to the bakeries they trust and will not consider brand switch. Results illustrated that expert advice in local stores is seen as not important for the participants.

\subsection{Findings of the management survey}

The overall response to management survey was very positive. Most management participants' opinions local e-commerce offers high potential and advantages. Three quarters $(75 \%)$ of the management participants indicated local e-commerce could be beneficial to their firms. A common view amongst respondents the implementation of local e-commerce could lead to revenue growth, increased productivity, customer satisfaction, and brand loyalty. The managerial perspectives in regards to the benefits of local e-commerce mirror to the consumers' views.

When asked "has your company use local e-commerce solutions in past 12 months?", $25 \%$ of the respondents said yes. This finding suggests a relatively low adoption of local e-commerce despite of the highly positive perceptions in regards to the benefits technological solution among the respondents. Respondents were asked to suggest reasons for not using online shopping in their companies. Challenges to implement e-

International Journal of Management and Applied Research, 2015, Vol. 2, No. 1 
commerce solutions in their companies include the uncertainties and costs associated with technological solutions as well as the need to provide staff training.

A common view amongst the participated managers was that local e-commerce should be part of a distribution-mix or complement existing distribution strategy instead of completely relying on online distribution channel in order to reduce potential risks. A minority of respondents mentioned that online distribution channel should be treated as discrete entity to the existing physical store.

Some respondents commented that e-commerce solutions should be used as a tool to maximise penetration into new markets. In particular, local e-commerce provides a means for small bakeries to produce customised, niche artisan baked products that are tailored to customer needs.

\section{Recommendations}

The results of this study have implications for practitioners in several areas. First, having multiple distributions channels - especially both physical and virtual channels is particularly suitable for bakeries. The demand for convenience is rising rapidly across the food industry since busy consumers would like to have quick meal which could be delivered and consumed in a relatively convenient manner. This could become a necessary trend to exploit in the bread and bakery products market in order to remain competitive in the market. An effective combination of physical stores with an online presence could enhance shopping experiences and thus create brand loyalty. The convenience to shop at anytime, everywhere is especially attractive to busy consumers. Innovative services such as click and collect services and multiple pick-up points, are making online shopping more appealing, especially for busy shoppers. Rather than waiting at home or office for the delivery of their online purchases, online shoppers can collect their goods at a time and place that are more convenient to them. Tesco, for example, allows their customers to shop online and pick up their groceries at the nearest stores or stations on the London Underground (Cumber, 2014). Furthermore, the rising trend of m-commerce indicates a growth opportunity for companies by offering smartphone users an option to shop via smartphone apps.

However, it is important to consider the operational difficulties and costs associated to implementing local e-commerce. Gaining customer trust can be difficult for online retailers due to concern of privacy and security. Many consumers do not make purchase online because their do not trust online retailers would secure their payment details and personal information (Tanh, 2000). On other hand, the complexities and costs of delivering perishable items are often greater than delivering non-perishable goods. For these reasons, local e-commerce may not suitable for micro bakeries which lack the capacity to deliver freshly baked goods. This leads to the second recommendation: build up a website for marketing purpose. Having an online presence could be useful for businesses to gain customer awareness (Muller et al., 2011; Niranjanamurthy et al. 2013; Zhang et al., 2013). At minimum level, bakeries and other small food retailers could use websites for informational purpose, i.e. describing the location of the physical stores, opening hours and phone number. On top of that, bakeries could specify and

International Journal of Management and Applied Research, 2015, Vol. 2, No. 1 
update their product range, baking process and product ingredients in the websites. The euro cucumber scare in 2011 and horsemeat scandals in 2013 are causing shoppers to become more conscious in the provenance of their food. Being explicit about the process food production could build consumer trust (Viktoria Rampl et al., 2012) and improve sales consequently.

Third, the online distribution channel could be particularly attractive for consumers looking for speciality products. The finding of this study shows that the over half $(60.66 \%)$ of the respondents would like to configure or customise their products online. This indicates a high potential of offering baked products in a variety of flavours and sizes as well as niche bakeries such as vegan and gluten free bakeries over the internet. In this way, speciality breads could be produced on demand thereby increasing efficiency and reducing food waste. In addition to that, specialty bakeries could be sold at higher prices in relative weight terms, and this will be a means of maximising profit margins.

\section{Conclusion}

This is an exploratory study of perceived use of local e-commerce in bakeries among consumers and managements in Germany. This paper has demonstrated that local ecommerce could bring several advantages to both consumers and bakeries. Results indicate that both consumer and management share similar perception regarding the potential benefits of local e-commerce, which include optimised revenue growth, increased efficiency, customer satisfaction, and brand loyalty. The finding is consistent with the scholarly works which maintained the advantages for merchants to adopt online channel as distribution channel (Heinemann et al. 2013; Muller et al. 2011; Niranjanamurthy et al. 2013; Porter 2001; Zhang et al. 2011).

This paper applied a theoretical framework (see figure 1) as a conceptual exploration tool for understanding local e-commerce solutions. This theoretical model expands the current knowledge of e-commerce, m-commerce, and local trade. Each element complements each other and an absence of one element could destabilise another.

The application of local e-commerce solutions can be expanded to other industries, such as gastronomy or butchery, or to other geographical areas. It would be insightful to examine how other food retailers exploit or perceive the opportunity of local ecommerce. Future research could examine the actual use of local e-commerce in the food industry, in comparison with various countries. Future study could also focus on the cultural differences in consumer behaviours when it comes to local e-commerce.

In summary, this exploratory study highlights the opportunity of local e-commerce which affects the selling and distribution of freshly baked products. The physical and digital channels complement each other in a way that allows both consumers and producers to be benefitted from local delivery of fresh bakery goods.

International Journal of Management and Applied Research, 2015, Vol. 2, No. 1 


\section{References}

1. Arnold, N. (2014). 3 Reasons Why Amazon Is Opening a Physical Retail Store. [online]. Available from: http://wallstcheatsheet.com/technology/3-reasons-whyamazon-is-opening-a-physical-retail-store.html/?a=viewall [Accessed 12 December 2014].

2. Bäckerei Konditorei Schmidt e.K. (2014). [online]. Available from: http://www.ihre-baeckerei-schmidt.de [Accessed 18 December 2014].

3. Burrell, G. and Morgan, G. (1982). Sociological Paradigms and Organisational Analysis. London: Heinemann.

4. Corbin , J. and Strauss, A. (2008). Basics of Qualitative Research. 3rd ed. Thousand Oaks, CA: Sage.

5. Cumber, R. (2014), "Tesco Click+Collect service launches at Hounslow West tube station", Get West London, [online]. Available from:

http://www.getwestlondon.co.uk/news/local-news/tesco-clickcollect-servicelaunches-hounslow-8336186 [Accessed 12 May 2015].

6. deVaus, D. A. (2002). Surveys in Social Research. 5th ed. London: Routledge.

7. Easterby-Smith, M., Thorpe, R., Jackson, P., \& Lowe, A. 2008. Management Research. 3rd ed. London: Sage.

8. Euromonitor (2013), Bakery products in Germany, Euromonitor International.

9. Gephart, J., and Robert, P. (2004). "Qualitative Research and the Academy of Management Journal", Academy of Management Journal. Vol. 47, No. 4, pp. 454-462. https://doi.org/10.5465/AMJ.2004.14438580

10. Hannah, D. R. and Lautsch, B. A. (2011). "Counting in Qualitative Research: Why to conduct it, when to avoid it, and when to closet it", Journal of Management Inquiry. Vol. 22, No. 1, pp. 14-22. https://doi.org/10.1177/1056492610375988

11. Heinemann, G., Haug, K., Gehrckens, M., and dgroup. (2013). Digitalisation of Commerce with e Pace - Digitalisierung des Handels mit ePace. G. Heinemann, K. Haug, M. Gehrckens, \& dgroup, eds. Wiesbaden: Springer Fachmedien Wiesbaden.

12. Heron, J. (1996). Co-operative Inquiry: Research into the Human Condition. London: Sage.

13. International Market Bureau (2010), Consumer trends: bakery products in Germany [Online], available from: http://www.gov.mb.ca/agriculture/marketprices-and-statistics/trade-statistics/pubs/germany_bakery_products_en.pdf [Accessed 12 May 2015].

International Journal of Management and Applied Research, 2015, Vol. 2, No. 1 
14. Khan, S. N. (2014), "Qualitative Research Method: Grounded Theory", International Journal of Business and Management. Vol. 9, No. 11, pp. 224233. https://doi.org/10.5539/ijbm.v9n11p224

15. Manzoor, A. (2010). E-commerce - An Introduction . Saarbrücken, Germany: LAP Lambert Academic Publishing GmbH \& Co. KG.

16. Miles, M. B. and Huberman, A. M. (1994). Qualitative Data Analysis. 2nd ed. Thousand Oaks, CA: Sage.

17. Muller, Y., Y.L. Thong, J. and Y.L. Thong, C. (2011). "Is Localization Advisable for E-commerce Websites?" In M. J. Shaw, \& W. T. Dongsong Zhang eds, E-Life: Web-Enabled Convergence of Commerce, Work and Social Life. Heidelberg: Springer-Verlag Berlin. 2011, pp. 255-260.

18. Niranjanamurthy, M., Kavyashree , N., Jagannath, S. and Dharmendra, D. (2013). "Analysis of E-commerce and M-Commerce: Advantages, Limitations and Security issues", International Journal of Advanced Research in Computer and Communication Engineering. Vol. 2, No. 6, pp. 2362-2364.

19. Porter, M. E. (2001), "Strategy and the Internet", Harvard Business Review, Vol. 79, No. 3, pp. 62-78.

20. Quin, Z. (2009) Introduction to the E-commerce. Berlin Heidelberg: SpringerVerlag GmbH Berlin Heidelberg.

21. Saunders, M., Lewis, P. and Thornhill, A. (2012). Research Methods for Business Students. 6th ed. London: Pearson.

22. Schwandt, T. A. (1997). Qualitative Inquiry: A Dictionary of Terms. London: Sage.

23. Strauss, A. and Corbin, J. (1998). Basics of Qualitative Research. 2nd ed. Thousand Oaks, CA: Sage.

24. Tanh, D. (2000). "Security issues in Mobile eCommerce", In K. Bauknecht, S. K. Madria, \& G. Pernul, eds. Electronic Commerce and Web Technologies. London: Springer-Verlag Berlin Heidelberg, pp.467-476.

25. Timmers, P. (2000). "Global and Local in Electronic Commerce", In K. Bauknecht, S. K. Madria, \& G. Pernul, eds. Electronic Commerce and Web Technologies. Heidelberg: Springer Verlag Berlin Heidelberg. 2000, pp.191205.

26. Viktoria Rampl, L., Eberhardt, T., Schütte, R. And Kenning, P. (2012) "Consumer trust in food retailers: conceptual framework and empirical evidence", International Journal of Retail \& Distribution Management, Vol. 40 No. 4, pp. $254-272$. 
27. Yin, R. K. (2009). Case Study Research: Design and Methods. 4th ed. Thousand Oaks, CA: Sage.

28. Yu, F. (2011). "Designing qualitative research", Organisation Management Journal, Vol. 8, No. 3, pp. 193-195. https://doi.org/10.1057/omj.2011.23

29. Zhang, B., Zhang, H. and Liu, B. (2011), "To Promote the Development of Retail E-commerce in Depth with Regional E-commerce”, In M. Dai, \& M. Dai, eds. Innovative Computing and Information. Suzhou: Springer-Verlag Berlin Heidelberg. 2011, pp. 437-445.

30. Zimmer, E. (1999). The Death of Retail. [online]. Available from: http://tenonline.org/art/9909.html [Accessed 12 November 2014]. 